\title{
Evaluation of sodium pool fire and thermal consequence in two-cell configuration
}

\author{
Takashi TAKATA*, Shuji OHNO* and Yuji TAJIMA** \\ *Japan Atomic Energy Agency \\ 4002 Narita, Oarai, Ibaraki 311-1393, Japan \\ E-mail: takata.takashi@jaea.go.jp \\ **ENO Suri Kaiseki Research \\ Funabashi, Chiba 273-0032, Japan
}

Received: 26 October 2016; Revised: 12 March 2017; Accepted: 6 June 2017

\begin{abstract}
Evaluation of accidental sodium leak, combustion, and its thermal consequence is one of the important issues to be assessed in the field of sodium-cooled fast reactor (SFR). The present paper deals with the sodium pool fire and subsequent heat transfer behavior in air atmosphere two-cell geometry both experimentally and analytically because such two-cell configuration is considered as a typical one to possess important characteristic of multi-compartment system seen in an actual plant. The analyses of the experimental data clarify the basic characteristics of sodium pool combustion and consequential heat and mass transfer in the cells, for instance, suggesting several features of multidimensional thermal-hydraulic behaviors such as the strong gas mixture at the combustion cell and the thermal stratification near the opening between the two cells. As a result of the numerical analysis using a lumped-parameter based zonal model safety analysis code 'SPHINCS', the applicability of the ventilation model implemented in SPHINCS has been demonstrated. It is also investigated that the buoyancy- driven ventilation is dominant in the experiment.
\end{abstract}

Key words : Sodium cooled fast reactor, Sodium fire, Thermal-hydraulics, SPHINCS, Computational simulation

\section{Introduction}

From the viewpoint of ensuring the safety of SFR plant, we take into account and postulate the accidental situation of liquid sodium leak and fire including severe accidental cases. Safety evaluation or more specifically probabilistic risk assessment and additional investigation of plant safety measures often necessitates numerical simulation tools to understand and quantify thermal loads to the plant building. For this purpose, several kinds of numerical tools has been developing in Japan Atomic Energy Agency (JAEA), such as a fast-running zone model, SPHINCS (Yamaguchi, et al, 2001, Yamaguchi and Tajima, 2003) and a multi-dimensional field model, AQUA-SF (Takata, et al., 2003).

At the same time, experimental studies have also been carried out to understand the important features and factors of sodium fire and subsequent heat/mass transfer behaviors, and to obtain the actual thermal-hydraulic data during the fire progression for being utilized as the models and codes validation. (Yamaguchi, et al., 2001, Ohno, et al., 2013 and Miyahara, et al., 2015)

In the previous experimental and code validation studies, sodium fire situations were mainly focused on, for instance 'spray' and 'pool' combustions in a single test section. (Yamaguchi, et al., 1998, 1999) On the other hand, an inside of an actual plant is segmented into many compartments and those are connected via openings. When sodium fire takes place in a compartment, ventilation through adjoining compartments affects the burning rate and spreading of sodium fire products (aerosol) significantly. The duration time of sodium fire and the mass and energy transport to adjoining compartments is of importance for an accident management against the sodium fire. Accordingly, the ventilation will be one of key issues for sodium fire in the actual plant. In the field model, the ventilation is automatically calculated by solving governing equations at the opening, whereas a constitutive equation for ventilation 
is implemented into the zone model.

The present paper deals with the sodium 'pool' fire in an air atmosphere especially in 'two-cell' configuration to investigate thermal-hydraulic interaction between the sodium burning cell and the neighboring non-burning cell caused by an opening between the cells. Based on the sodium pool fire experiment and measurement, typical physical process data of temperature in various positions of gas region and structures in the test apparatus are described and analyzed. Furthermore, numerical simulation using the zone model SPHINCS is also performed so as to investigate the code applicability especially in terms of the ventilation effect.

\section{Sodium fire experiment in two-cell configuration 2.1 Experimental apparatus}

The sodium fire experiment in two-cell configuration was conducted at Oarai Research and Development center in JAEA. The test apparatus (named 'SOLFA1') was set at SAPFIRE facility (Himeno, et al., 1988). The schematic of the test apparatus is shown in Fig. 1. The rectangular-shaped cell was $4.57 \mathrm{~m}$ in length, $4.88 \mathrm{~m}$ in width and $3.24 \mathrm{~m}$ in height. The test cell (identified as 'Run-D3') was further divided into two cells as in Fig. 1 by a partitioning wall with an opening between the two cells: sodium combustion cell (Cell-1) and neighboring cell (Cell-2). In Cell-1, a sodium catch pan of $0.15 \mathrm{~m}$ square was placed and a pool type sodium combustion was put in execution. The expanded atmospheric gas and smoke-like aerosols of sodium combustion products were transported to the 'neighboring cell' through the opening with $4.88 \mathrm{~m}$ in width and $0.2 \mathrm{~m}$ in height, and finally to the outside region of the test cell through an exhausting vent duct in the neighboring cell. Ceiling, floor, and all the walls of the test apparatus were made of reinforced concrete with thickness of $0.2 \mathrm{~m}$ or $0.3 \mathrm{~m}$, that were lined with thermal insulator and carbon steel plates.
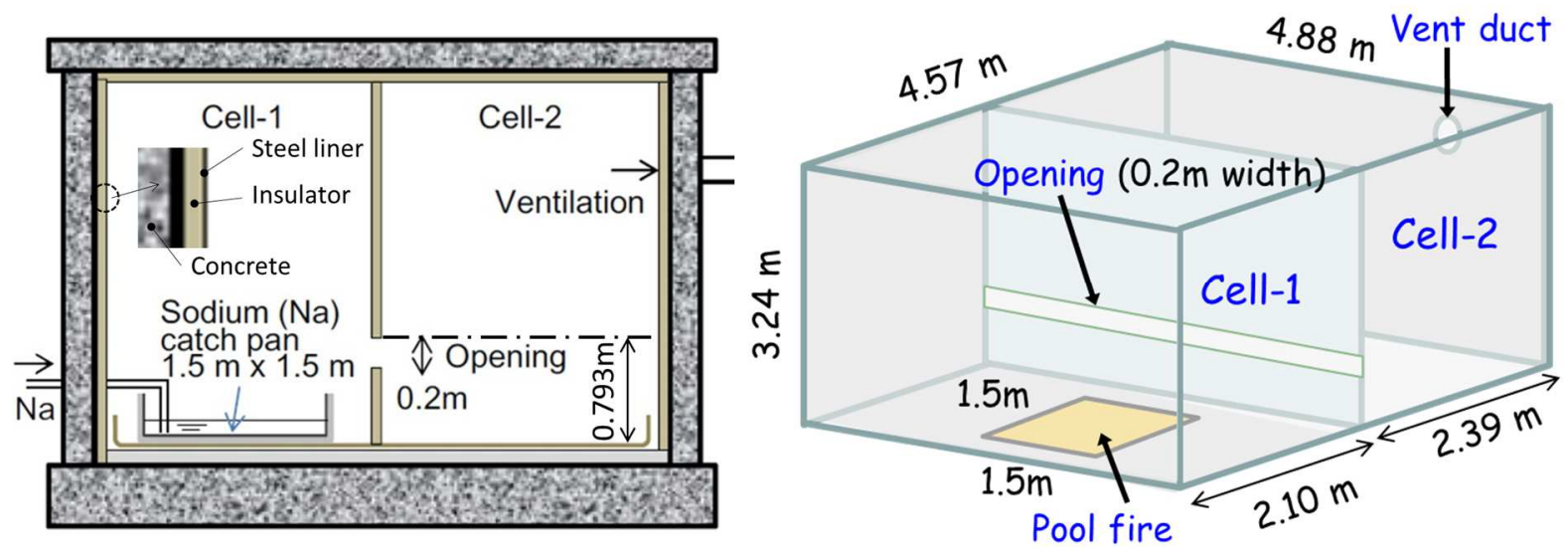

Fig. 1 Test apparatus consists of two adjoining cells via an opening of $4.88 \mathrm{~m}$ in width and $0.2 \mathrm{~m}$ in height. A pool type sodium combustion is put in execution in Cell-1 and energy and mass (aerosol of sodium combustion products) transfer between cells through the opening is observed.

\subsection{Experimental conditions}

Table 1 shows the outline of experimental conditions. After sodium pre-heating, totally $55 \mathrm{~kg}$ of sodium pool with surface area of $2.25 \mathrm{~m}^{2}(1.5 \mathrm{~m} \times 1.5 \mathrm{~m})$ was rapidly made within 2 minutes in a carbon-steel-made catch pan on the floor of Cell-1. Initial atmosphere in the cells was air, containing about $21 \mathrm{vol} \%$ oxygen as the constituent. The test cells were not confined, thus the gas was ventilated so that the thermally expanded gas and generated aerosols particles were discharged from the vent duct to the downstream smoke exhausting system.

In order to analyze sodium fire and heat transfer behavior during for one hour in the experiment, measurements were made for the temperatures around the sodium pool, of gas, of cell structures, gas pressure in the cell, oxygen concentrations in two cells, and for the aerosols concentrations in two cells. The temperature were measured with K-type thermocouples for 9 points near the sodium pool, 12 points on the catch pan surface, 57 positions in the gas region within the cells, and 44 points on the inner surface of cell structures. Figure 2 and Table 2 summarize typical 
positions of gas temperature measurement both in Cell-1 and Cell-2.

Table 1 Experimental conditions

\begin{tabular}{c|c}
\hline \hline Size of catch pan & $2.25 \mathrm{~m}^{2}(1.5 \mathrm{~m} \times 1.5 \mathrm{~m})$ \\
\hline Thickness of catch pan & $4.5 \mathrm{~mm}$ \\
\hline Amount of supplied sodium & $55 \mathrm{~kg}$ \\
\hline Initial sodium temperature & $500^{\circ} \mathrm{C}$ \\
\hline Duration of sodium supply & $2 \mathrm{~min}$ \\
\hline Initial atmosphere in cells & $\mathrm{Air}$ \\
\hline Initial temperature in cells & $19^{\circ} \mathrm{C}$ \\
\hline
\end{tabular}

Table 2 Dimensions of dominant thermocouples

\begin{tabular}{c|c|c:c}
\hline \hline Thermocouple & $\begin{array}{c}\text { Dimension } \\
\mathrm{x} \times \mathrm{y} \times \mathrm{z}(\mathrm{m})\end{array}$ & Thermocouple & $\begin{array}{c}\text { Dimension } \\
\mathrm{x} \times \mathrm{y} \times \mathrm{z}(\mathrm{m})\end{array}$ \\
\hline \hline TG101 & $4.05 \times 0.30 \times 2.94$ & TG201 & $0.30 \times 2.48 \times 1.62$ \\
\hline TG102 & $2.44 \times 0.30 \times 2.94$ & TG208 & $2.44 \times 2.48 \times 2.94$ \\
\hline TG109 & $0.30 \times 1.17 \times 2.94$ & TG209 & $2.44 \times 3.38 \times 2.94$ \\
\hline TG110 & $1.37 \times 1.17 \times 2.94$ & TG210 & $2.44 \times 4.27 \times 2.94$ \\
\hline TG111 & $2.44 \times 1.17 \times 2.94$ & TG211 & $2.44 \times 2.48 \times 1.62$ \\
\hline TG112 & $3.51 \times 1.17 \times 2.94$ & TG212 & $2.44 \times 3.38 \times 1.62$ \\
\hline TG113 & $4.58 \times 1.17 \times 2.94$ & TG213 & $2.44 \times 4.27 \times 1.62$ \\
\hline TG114 & $2.44 \times 1.17 \times 2.11$ & TG214 & $2.44 \times 2.48 \times 0.30$ \\
\hline TG115 & $0.30 \times 1.17 \times 1.62$ & TG215 & $2.44 \times 3.38 \times 0.30$ \\
\hline TG116 & $1.37 \times 1.17 \times 1.62$ & TG216 & $2.44 \times 4.27 \times 0.30$ \\
\hline TG117 & $2.44 \times 1.17 \times 1.27$ & TW102 & $2.44 \times 0.00 \times 2.84$ \\
\hline TG118 & $0.55 \times 1.17 \times 0.44$ & TW105 & $2.44 \times 0.00 \times 2.11$ \\
\hline TG119 & $1.37 \times 1.17 \times 0.44$ & TW111 & $4.88 \times 0.40 \times 2.81$ \\
\hline TG120 & $2.44 \times 1.17 \times 0.44$ & TW203 & $2.44 \times 4.57 \times 1.95$ \\
\hline TG127 & $4.05 \times 1.80 \times 1.27$ & TW208 & $0.82 \times 2.58 \times 3.24$ \\
\hline & & &
\end{tabular}
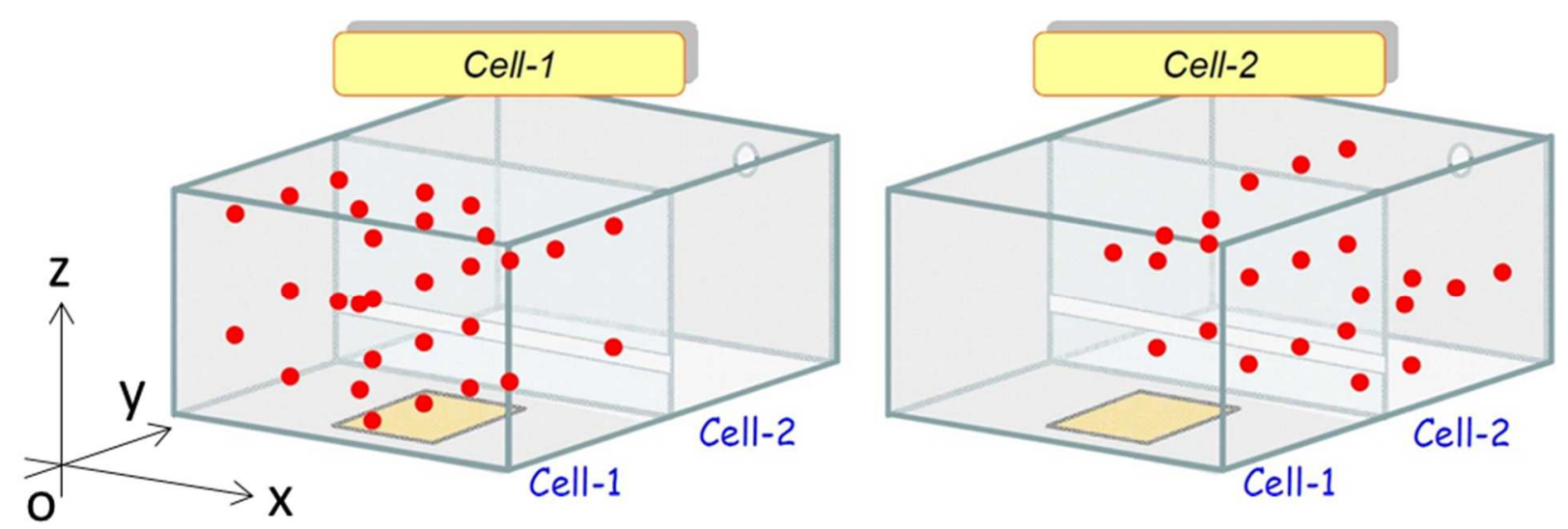

Fig. 2 The position of thermocouple for gas temperature measurement is shown as a red symbol with bird's-eye view.

\subsection{Experimental results and discussion}

\subsubsection{Outline of sodium combustion and heat transfer}

Figure 3 shows typical measured results for temperatures and oxygen concentrations in the cells, with suggests 
characteristic heat transport phenomena due to the sodium fire. The spatially averaged temperature is plotted in the figure for catch pan and gas in the cells. It is seen in Fig. 3(a) that the initiation of sodium combustion has heated up the sodium catch pan whose temperature would not far from that of liquid sodium pool. The sodium combustion heat was transported from pool to gas in Cell-1 at first by convective and radiation heat transfer, to the gas in Cell-2 next by heat/mass transfer through the rectangular opening between the cells.

Figure 3(b) shows oxygen concentration data measured in the both cells, which indicates the oxygen consumption with time due to the burning of sodium. However, very small difference observed in the measured data in two cells seems not to be reasonable. The two curves in Fig. 3(b) tell us that the oxygen concentrations in two cells have changed almost in the same way, but this interpretation might not be correct possibly due to the difference in the gas sampling time delay between the two measurements of oxygen concentration in Cell-1 and Cell-2.

In the last one of Fig. 3(c), the temperature difference of 30 to $70^{\circ} \mathrm{C}$ appeared between the structure surface and the gas near the structure both in the combustion cell and the neighboring cell. These data can be utilized to confirm the validity of numerical models such as a similarity of heat/mass transfer models between the cells. Sodium burning rate was roughly estimated from the decreasing tendency of oxygen concentration though the uncertainty of estimation might be large due to the above-mentioned possible measurement error. Figure 3(b) indicates roughly constant oxygen consumption rate of about $0.41 \mathrm{vol} \% / \mathrm{min}$, thus we calculate oxygen mass consumption rate and sodium burning rate from Eq. (1) considering the ideal gas law and assuming the mole ratio of sodium combustion reaction product as: $\mathrm{Na}_{2} \mathrm{O} / \mathrm{Na}_{2} \mathrm{O}_{2}=1$.

$$
w=\sum_{i=1,2} \frac{P_{i} V_{i} M}{R T_{\text {gas }, i}}
$$

Here, $w$ is the oxygen amount, $M$ is molecular weight of oxygen, $P$ and $T$ are the pressure and the temperature of gas in the cell, $V$ is the volume of the cell and $R$ is the gas constant. The subscript $i$ denotes the cell number. The calculated sodium burning rate at $10 \mathrm{~min}$ after the start of experiment, when the oxygen concentration was relatively higher, becomes about $14 \mathrm{~kg}-\mathrm{Na} / \mathrm{m}^{2} / \mathrm{hr}$. Comparing with 17 to $20 \mathrm{~kg}-\mathrm{Na} / \mathrm{m}^{2} / \mathrm{hr}$ reported by Malet (1996) in a typical sodium pool fire configuration, the similar sodium combustion rate was obtained even in the present cell configuration.

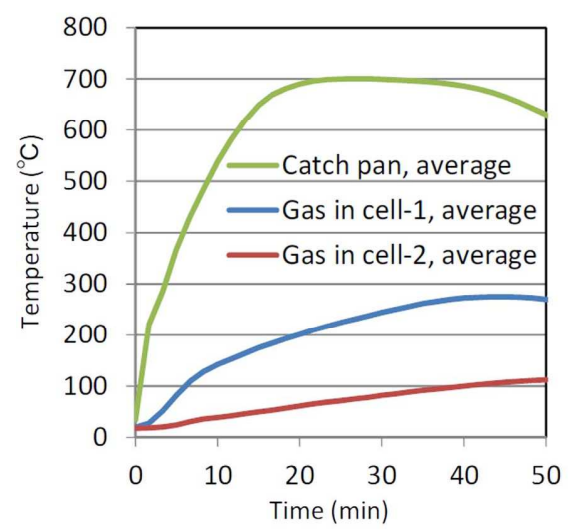

(a) Averaged catch pan and gas temperature

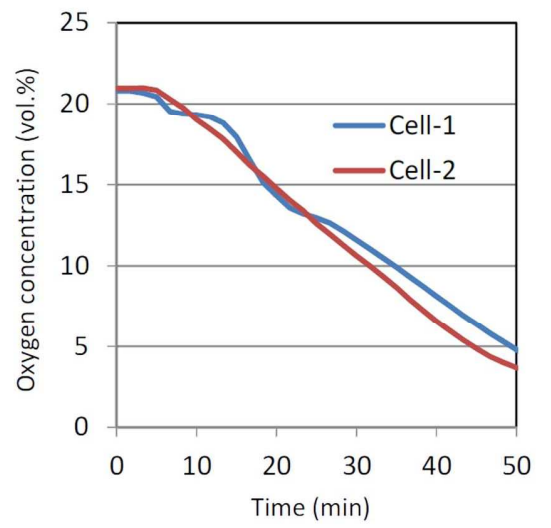

(b) Oxygen concentration in cells

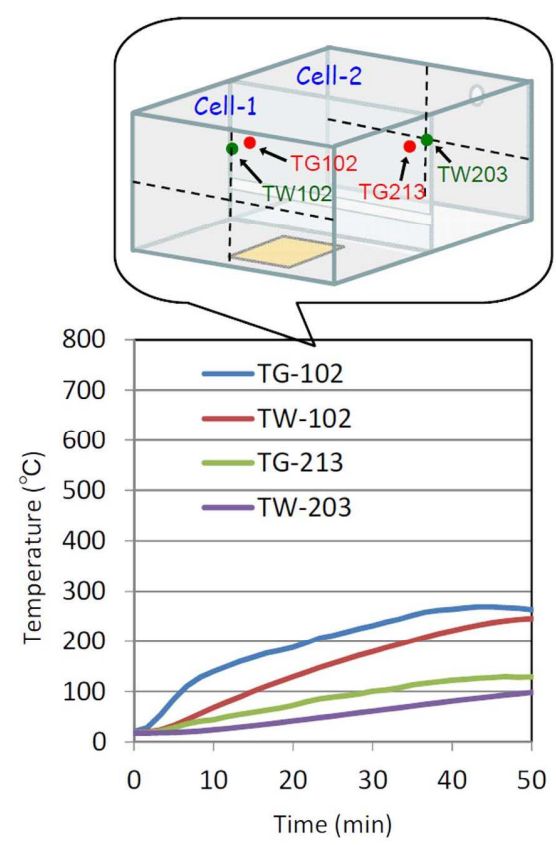

(c) Typical gas and wall temperatures

Fig. 3 The catch pan temperature becomes high due to the contact with liquid sodium. The temperature difference between the cells is approximately $100-200^{\circ} \mathrm{C}$, while almost the same oxygen concentration is observed in Cell-1 and Cell-2. Furthermore, taking into account the similar temperature difference between the wall and adjoining gas in Cell-1 and Cell-2, the similarity of the heat/mass transfer models will be achieved regardless of the cells. 


\subsubsection{Heat transport in gas region}

Figure 4 indicates each temperature trend in a vertical cross section both for Cell-1 and Cell-2. As shown in the left side of Fig.4, no remarkable temperature profile is observed in a vertical cross section of Cell-1 except for several measurement points TG-120, TG-117 and TG-114. Considering those three thermocouples response, there seems to be larger temperature difference in vertical direction just above sodium pool. This tendency will be interpreted that the combustion heat has made the high temperature gas region near burning sodium pool due to radiation heat transfer. Thus, the radiation heat transfer from high temperature pool surface or burning flame might be one of the important mechanism of gas heating in this region.

The radiation transmittance of sodium aerosols-suspended atmosphere is shown in Fig. 5 (Ohno, 2005). A fitting curvature based on an exponential function is also plotted (solid line in Fig.5). Since the aerosol caused by sodium fire products is invisible, it affect the radiation heat transfer significantly in accordance with the increase of the aerosol concentration. Figure 6 shows the time transient of the aerosol concentration both in Cell-1 and Cell-2. The time delay of the increase of the concentration was observed at the beginning in Cell-2. Then almost the constant value of 10 $20 \mathrm{~g}-\mathrm{Na} / \mathrm{m}^{3}$ was measured both in the cells after $10 \mathrm{~min}$ from the experiment start. It is apparent that the aerosol concentration at the combustion region (near above the catch pan) became much higher than $10-20 \mathrm{~g}-\mathrm{Na} / \mathrm{m}^{3} \mathrm{resulting}$ in the high temperature region near above the catch pan due to the radiation heat transfer.

On the other hand, the gas temperatures in Cell-2, shown in the right-hand side of Fig. 4, indicate a special feature. There is clear temperature difference between the gas region above and below the level of the opening in cell partitioning plate. The temperature difference is about $30^{\circ} \mathrm{C}$ at $20 \mathrm{~min}$ and about $60^{\circ} \mathrm{C}$ at $50 \mathrm{~min}$ from the experiment initiation. This is considered that a thermal stratification occurred when the heated and expanded gas in Cell-1 flowed into Cell-2 through the opening and the buoyancy effect overcame the inertia of the flow in Cell-2. Moreover, in the upper part region of Cell-2, gas temperatures near the ceiling were several degrees Celsius higher than those at middle position and at the same time the gas temperature near the central position of Cell-2 (TG-212) was lower than other positions. This implies that the thermal stratification resulted in slight temperature gradient in the upper region of Cell-2 as well, and that the transported high temperature gas from Cell-1 to Cell-2 circulated mildly in the cell along ceiling and sidewall surface in the upper region of Cell-2.
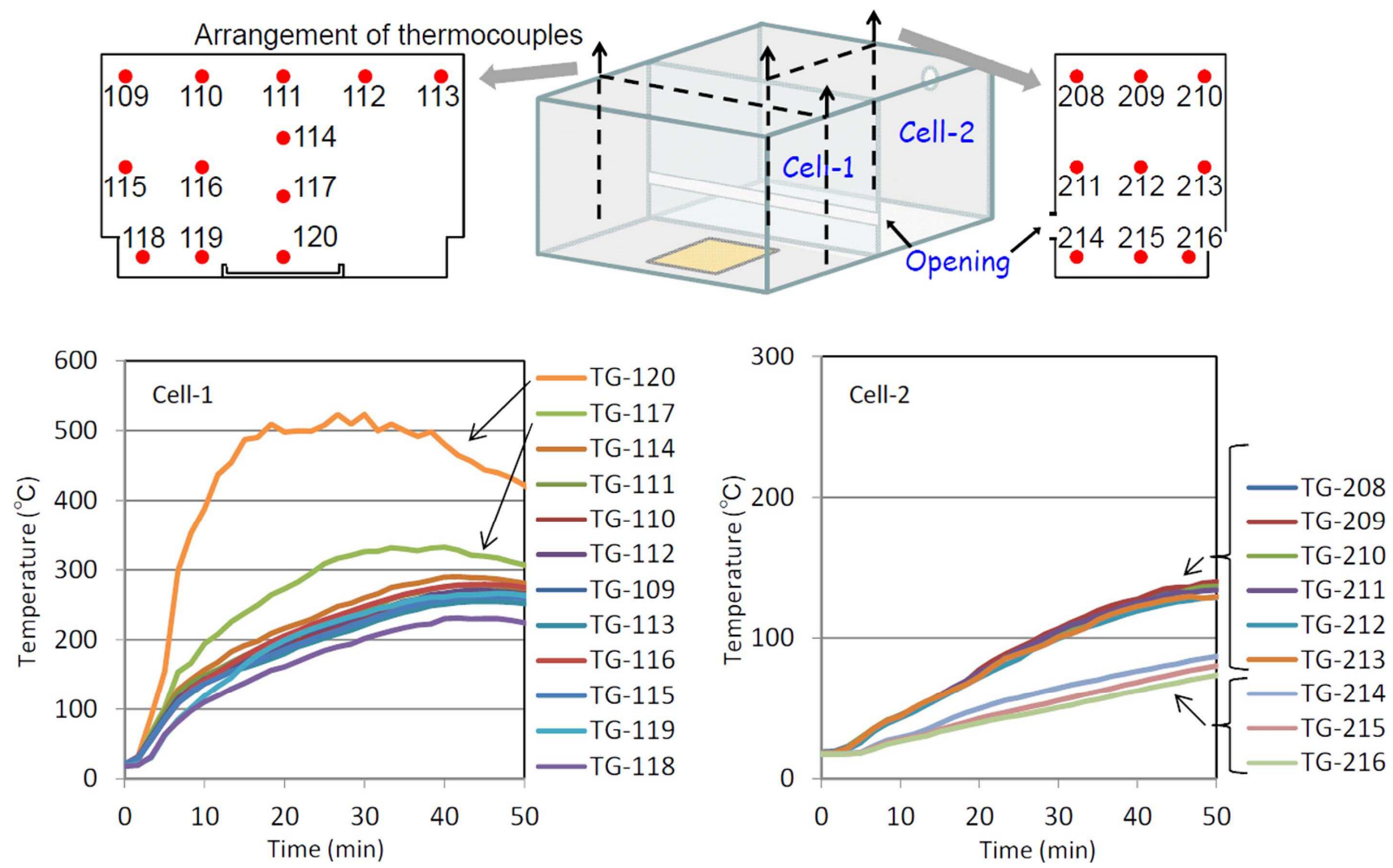

Fig. 4 The high gas temperature region appears at near above the catch pan in Cell-1 (TG-120). This might suggest the 
importance of radiation heat transfer from the combustion area to adjoining atmosphere. In Cell-2 (right side of viewgraph), the thermal stratification caused by the opening is clearly observed.

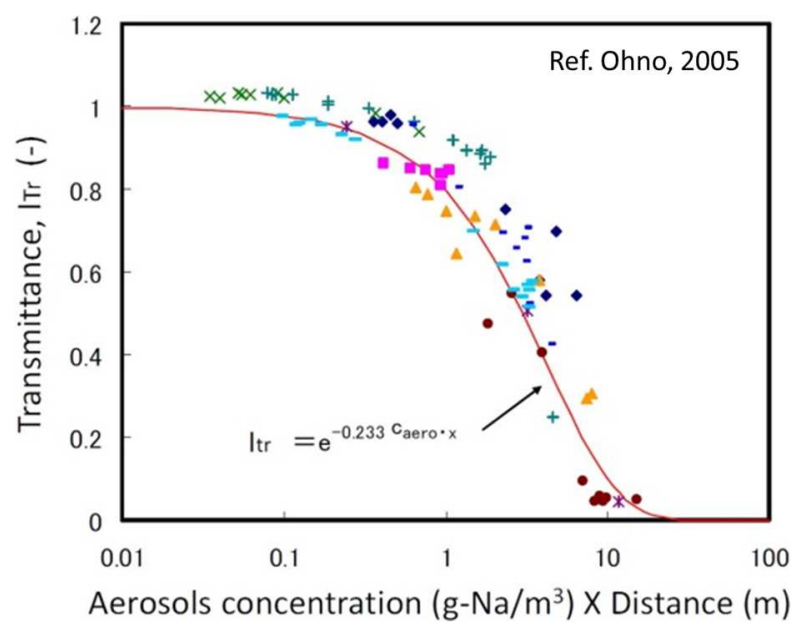

Fig. 5 Since aerosol of sodium fire products is invisible, the aerosol concentration will affect the radiation heat transfer significantly when the aerosol concentration $\times$ the distance $\left(\mathrm{C}_{\text {aero }} \cdot \mathrm{x}\right.$ in equation) exceeds 10 (Ohno, 2005).

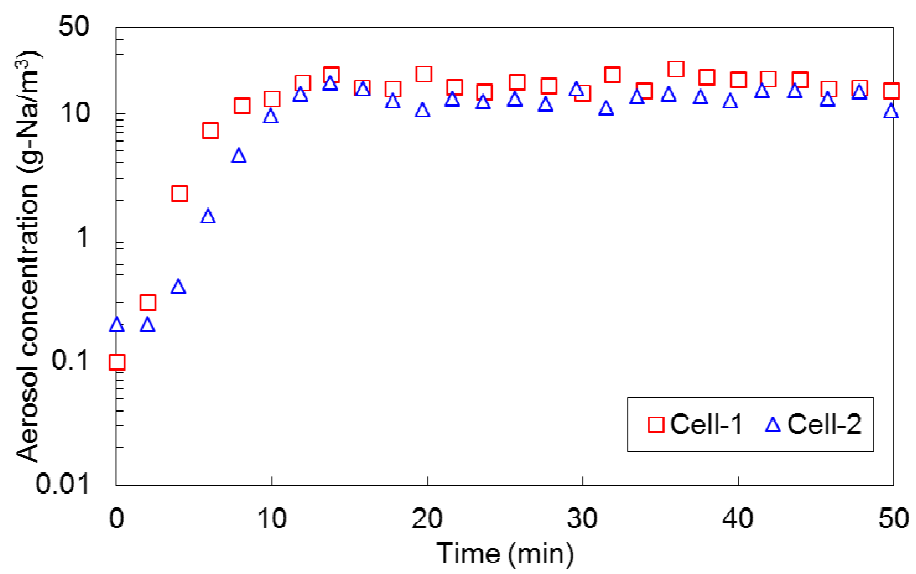

Fig. 6 At the begging of the experiment, a delay of aerosol concentration is observed in Cell-2. Then, almost constant value of $10-20 \mathrm{~g}-\mathrm{Na} / \mathrm{m}^{3}$ is measured after $10 \mathrm{~min}$ from the experiment start.

\section{Analysis with sodium fire code SPHINCS}

\subsection{Outline of SPHINCS and computational condition}

Numerical simulation using the SPHINCS code (Yamaguchi, et al., 2003) was conducted for the purpose to confirm the validity of the code especially in terms of a ventilation effect between the cells and further, to analyze and discuss the experimental results more in detail. SPHINCS is a zone-model based sodium fire analysis code, calculating sodium combustion in spray and pool forms and subsequent heat/mass transfer behaviors in a multi-cell system. The governing equations of mass and energy are shown in the following.

$$
\begin{gathered}
\int \frac{\partial \rho_{i}}{\partial t} d V_{i}+\sum_{j}\left(\int \rho u_{j} d S_{j}\right)=G_{i} \\
\int \frac{\partial \rho_{i} C p_{i} T_{i}}{\partial t} d V_{i}+\sum_{j}\left(\left.\int \rho u C p T\right|_{j} d S_{j}\right)+\sum_{k}\left(\left.\int q_{b}\right|_{k} d S_{k}\right)=Q_{i}
\end{gathered}
$$

Here, $\rho$ and $u$ are the density and the velocity at the junction $j$ respectively. $S$ and $G$ are the area of the junction and the source term of mass in cell $i$ due to such as the chemical reaction. $C p$ is the specific heat and $q_{b}$ is the heat flux at the 
wall boundary $k . Q$ is the energy source term.

The schematic of the code is illustrated in Fig. 7. In this code, sodium pool combustion is calculated by estimating the mass conservation of the reactants at burning flame region above sodium pool surface; i.e. both the oxygen mass flux from the atmosphere and sodium vapor mass flux from sodium pool to the flame, with determining the reaction products under the assumption of instantaneous chemical equilibrium. Convective and radiation heat transfer from gas to the ambient structures is calculated from the temperature difference between gas and structure surface with considering the heat transfer rate which is estimated by various empirical correlations. Also modeled in the code is mass transfer between cells due to (i) pressure-difference-driven flow and (ii) temperature-difference (buoyancy)-driven natural convective flow. The former is calculated in the SPHINCS code taking into account the conservation of mass and user-specified pressure loss coefficient at the junction of the cells. The latter convective flow between two cells is calculated from gas temperatures of the cells and the semi-empirical correlations proposed by Brown (1962) or Brown and Solvason (1962) in which the size parameters of the opening affect to the flow intensity.

In a horizontal ventilation (ventilation through vertical partitions), the volumetric ventilation rate $\left(Q_{v}\right)$ is evaluated in the following equation.

$$
\begin{aligned}
& q=Q_{V} \bar{\rho} \overline{C p} \Delta T, h_{T}=\frac{q}{W H \Delta T}, N u=\frac{h_{T} H}{\lambda}=\frac{C}{3} \operatorname{Pr} \times G r^{1 / 2} \\
& \therefore Q_{V}=\frac{\lambda W}{\bar{\rho} \overline{C p}} \frac{C}{3}{\operatorname{Pr} G r^{1 / 2}}^{1 / 2}
\end{aligned}
$$

Here, $W$ and $H$ are the width and the height of the opening respectively. $h_{T}$ is the heat transfer coefficient and $\lambda$ is the thermal conductivity. $P r$ and the $G r$ are the Prandtl number and the Grashof number respectively. $C$ is the empirical constant and set to 0.6-1.0 (Brown, et al., 1962). In SPHINCS code, $C$ is set to 0.77. The overbar indicates the average between cells.

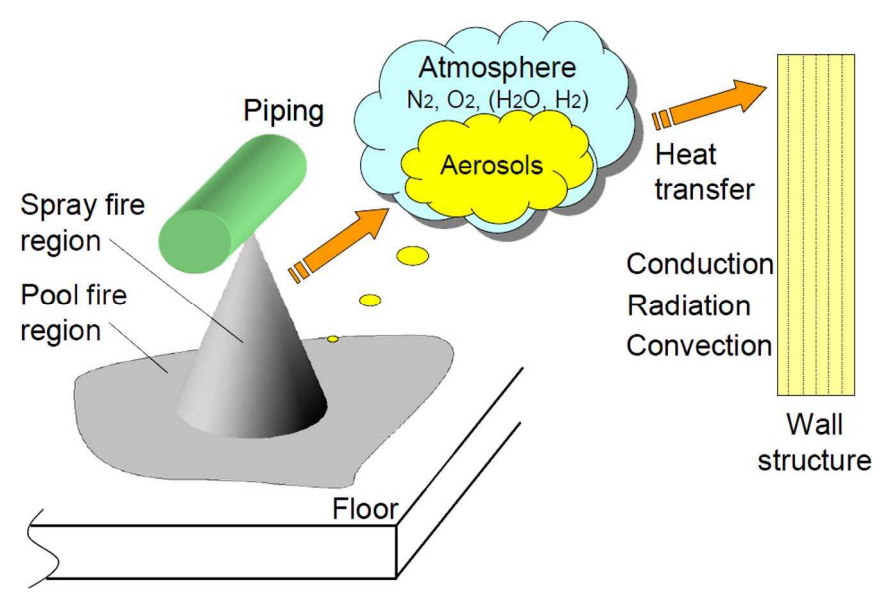

Fig. 7 In SPHINCS code, both spray and pool type sodium combustions are modeled (the spray combustion is out of target in the present experiment).

Figure 8 shows the schematic of computational model. In the simulation, the geometry of experimental apparatus, Cell-1 and Cell-2, were modeled so that the surface area and heat capacity of the media in the simulating domain were approximately equivalent to those in the experiment. It is noted that the coefficient of pressure loss at the opening was set to 1.5 as a simplified sudden-contracted and -expanded flow. 


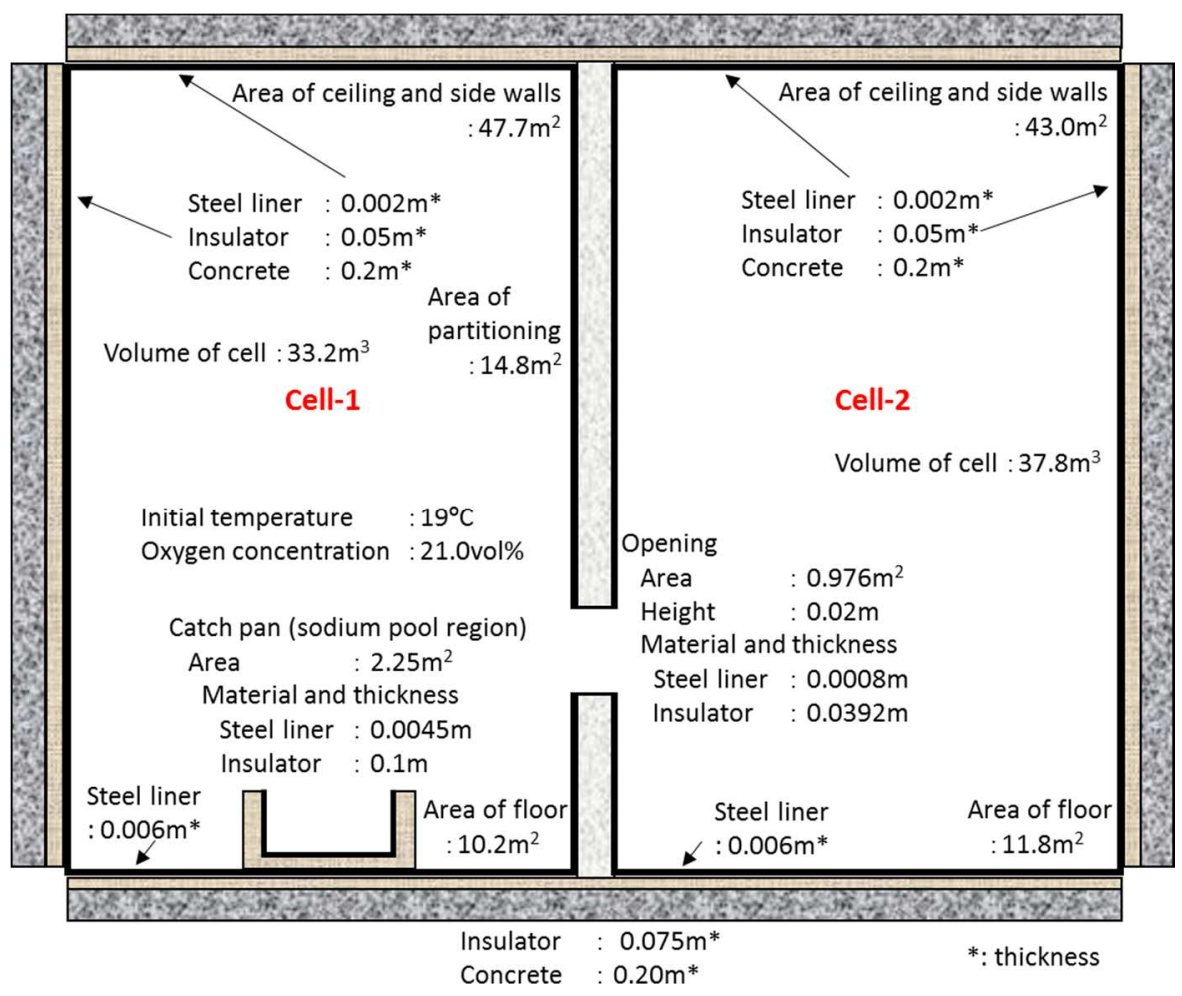

Fig. 8 Since a lumped model is applied to SPHINCS, major inputs are the volume and area of cell. Outermost boundary of concrete is treated as an adiabatic condition.

\subsection{Numerical results and discussion}

Figure 9 shows the comparison of the calculated results with SPHINCS and the measured data of; (a) sodium catch pan temperature, (b) gas temperatures and (c) structure surface temperatures. Bold lines in the figure denote SPHINCS results and thin lines are the measured data.

With regard to the catch pan temperature, the computational result (bold line) agrees with the measured data of TP101 although the peak temperature is slightly underestimated in the computation. However, the delay of the temperature increase was observed in the experiment (thin lines). As shown in Table 1, the feeding of liquid sodium on the catch pan was finished at 120s. Therefore, the temperatures would increase simultaneously when uniform pool combustion took place at the catch pan in the experiment. Probably, a multi-dimensional effect, such as a flow, gas temperature and oxygen concentration distributions caused the difference of the increase transient.

The temperatures of gas and structure surface at various positions both in Cell-1 and Cell-2 are very well reproduced by the SPHINCS code as shown in Fig. 9. Except for remarkably low measured temperatures of floor surface and gas near the floor in Cell-2 due to the thermal stratification, the calculated temperatures of other gas and wall surface are in good agreement with measured data.

The comparison of the calculated aerosol concentration with measured data is shown in Fig. 10. Although the measured concentration was higher than that of computation at $500-1000 \mathrm{~s}$, the initiation of the measured concentration increase and time delay at Cell-2 have a good agreement with the computation as well as the maximum value (approximately $10-20 \mathrm{~g}-\mathrm{Na} / \mathrm{m}^{3}$ ). Consequently, it is demonstrated that the present computational model of sodium fire analysis code SPHINCS is valid to evaluate the sodium pool fire and subsequent heat/mass transfer behaviors in a horizontally connected two-cell configuration. 


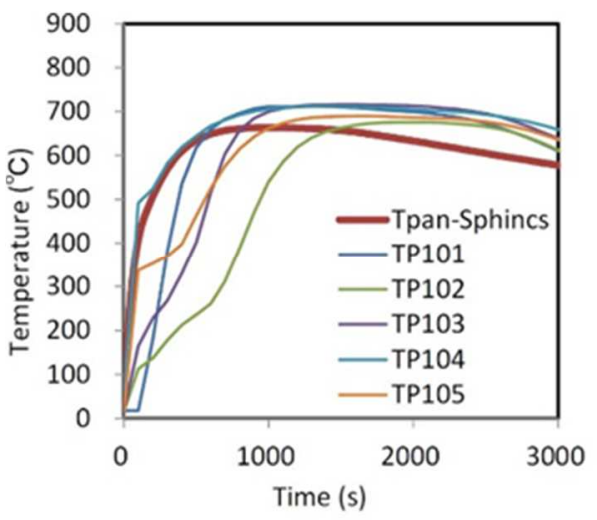

(a) Catch pan temperature

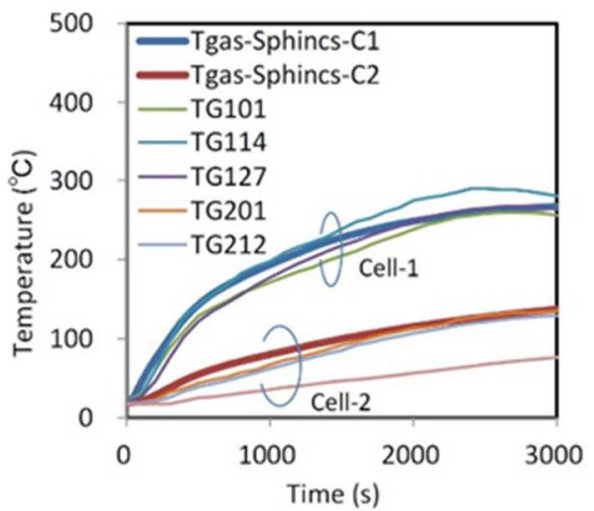

(b) Gas temperature
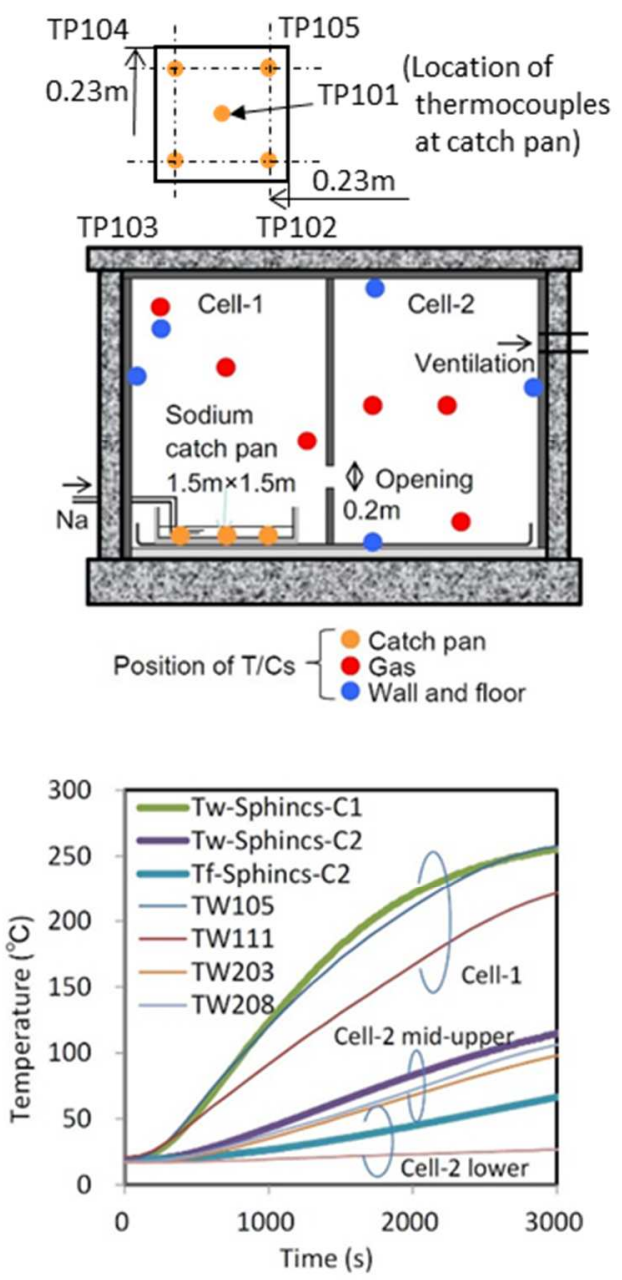

(c) Wall and floor temperature

Fig. 9 Except the thermal stratification region (bottom side of Cell-2), a good agreement is obtained between the experiment and numerical analysis. Since the opening is located at a lower height, it might be said that the thermal stratification has less influence on the average temperature of each cell, which is evaluated in the numerical analysis.

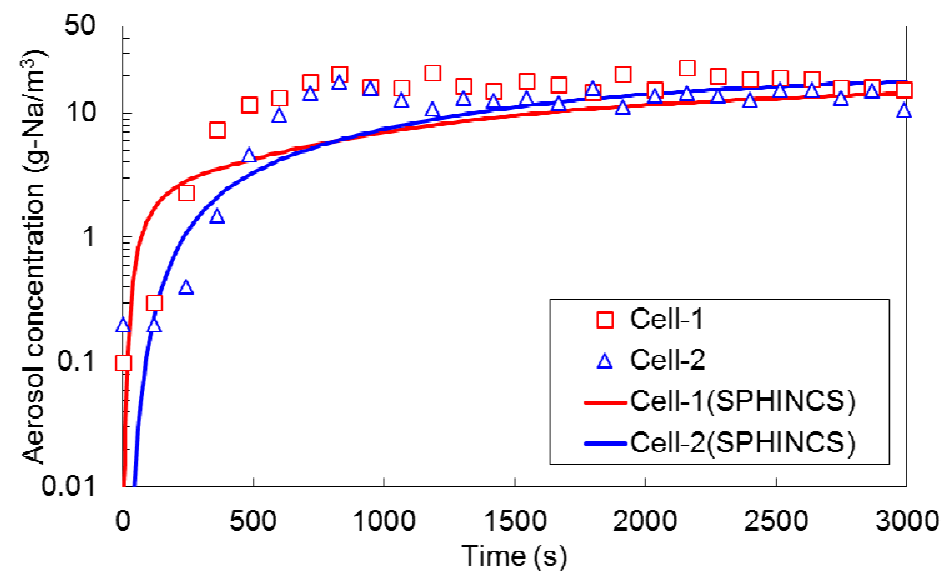

Fig. 10 In the computation, the aerosol concentration is increasing slightly after 2000s. However, the time delay due to the ventilation through the opening is well simulated as well as the maximum concentration.

Since a comparative good agreement is achieved in the numerical analysis with SPHINCS code and there was no 
measured data in terms of the ventilation rate, let us discuss the ventilation characteristics from the computational result. The gas flow rates at the opening calculated by SPHINCS are plotted in Fig. 11. We can notice from Fig. 11 that the temperature-difference-driven natural convection flow at the opening is approximately 3 to 4 times higher than pressure-difference-driven flow for most of time range in the experiment. This dominant convective flow rate is roughly $0.17 \mathrm{~kg} / \mathrm{s}$. This corresponds to the heat transport of approximately $20 \mathrm{~kW}$. It is almost equivalent to $20 \%$ of the sodium pool combustion estimated from the sodium burning rate of $14 \mathrm{~kg}-\mathrm{Na} / \mathrm{m}^{2} / \mathrm{h}$ obtained in the section 2.3 .1 . It is apparent that the ventilation effect is of importance for sodium combustion phenomenon with multi-cell configuration.

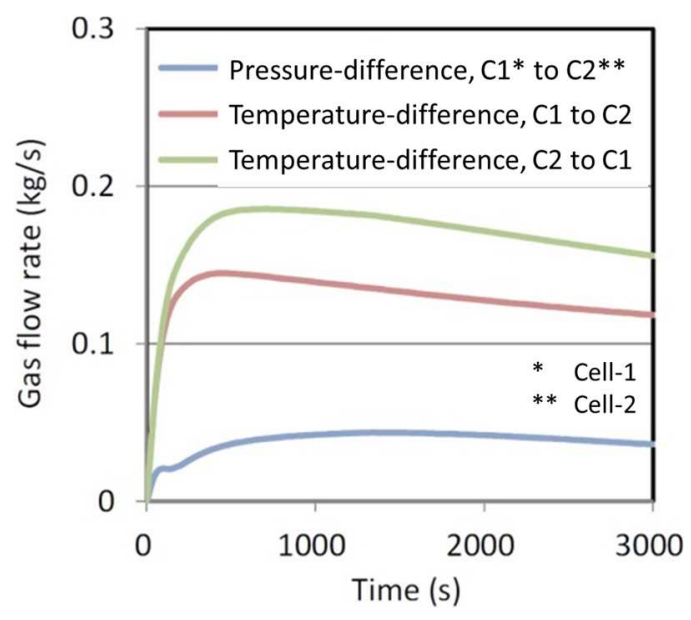

Fig. 11 In Brown's model, the exchange volumetric flow rate at the opening is assumed to be equivalent. Hence the discrepancy of the mass flow rate (green and red lines) is investigated. The total mass flow rate seems to be conserved by additional pressure-driven flow.

\section{Conclusion}

In this study, both experimental and numerical studies have been carried out to investigate a sodium pool fire phenomenon with a horizontally connected two-cell configuration system. The conclusion of the measure date analyses are summarized as follows:

1) The experimentally obtained data are considered valuable since they provide important information for the sodium fire and its consequences in the two-cell configuration system.

2) Typical behaviors observed in two-cell system experiment with an opening between the cells are;

- fairly strong gas mixing in a combustion cell and subsequent small gas temperature difference in the cell,

- thermal stratification behavior in the neighboring cell around the vertical level of opening between the cells,

- relatively mild circulation of higher temperature gas that enters from combustion cell into the neighboring cell, and

- important behavior of convective mass transfer at the opening between the cells driven by the temperature difference.

As a result of the numerical simulation using the zone model SPHINCS code, it is demonstrated that the temperature of the catch pan in the burning cell, the gas and the wall temperature in each cell agree with the experimental result. Thus, the ventilation effect is correctly evaluated in the code. Consequently, it is concluded that SPHINCS code has applicability to investigate sodium fire accident with multi-compartments configuration. It is also found that the ventilation due to the temperature-difference-driven convection is dominant in the experiment.

\section{References}

Brown, W. G., Natural convection through rectangular openings in partitions-2 Horizontal partitions, International Journal of Heat Mass Transfer, Vol. 5 (1962), pp.869-878.

Brown, W. G. and Solvason, K. R., Natural convection through rectangular opening in partitions-1 Vertical partitions, International Journal of Heat Mass Transfer, Vol. 5 (1962), pp. 859-868. 
Himeno, Y., Miyahara, S., Morii, T. and Sasaki, K., Engineering scale test on sodium leak and fire accident and its consequences in auxiliary building of fast breeder reactors, Proceedings of the fourth International Conference on Liquid Metal Engineering and Technology (LIMET) (1988), Paper No. TS-15 \#202.

Malet, J. C., Ignition and combustion of sodium, fire consequences, extinguishment and prevention, Proceedings of International Atomic Energy Agency, International Working Group on Fast Reactors (IWGFR-92) (1996), p.13-37.

Miyahara, S., Seino, H., Ohno, S. and Konishi, K., Development of fast reactor containment safety analysis code, CONTAIN-LMR (1) Outline of development project, Proceedings of the 23rd International Conference on Nuclear Engineering (ICONE-23) (2015), Paper No. ICONE23-1586.

Miyake, O., Seino, H., Takai, T. and Hara, H., Development of CONTAIN code for FBR sever accident analysis, Proceedings of the fourth International Conference on Design and Safety of Advanced Nuclear Power Plants (ANP'92) (1992), p.41.4-1 - 41.4-5.

Ohno, S., Measurement of thermal radiation transmission in a sodium aerosols suspended atmosphere, Japan Atomic Energy Agency Technical Report (2005), Report No. JNC TN9400 2005-40 (in Japanese).

Ohno, S., Hamase, E. and Kamide, H., Ongoing validation of sodium fire analysis code system for SFR safety evaluation, Proceedings of International Congress on Advances in Nuclear Power Plants (ICAPP2013) (2013), Paper No. FF228.

Takata, T., Yamaguchi, A., Maekawa, I., Numerical Investigation of Multi-Dimensional Characteristics in Sodium Combustion, Nuclear Engineering and Design, 220 (2003), pp. 37-50.

Yamaguchi, A. and Tajima, Y., Validation analysis of pool fire experiment (Run-F7) using SPHINCS code, Japan Atomic Energy Agency Technical Report (1998), Report No. PNC TN9410 98-070 (in Japanese).

Yamaguchi, A. and Tajima, Y., Development and validation of SPHINCS program for FBR sodium fire analysis -study on droplet combustion and unresolved issues in spray fire modeling-, Japan Atomic Energy Agency Technical report (1999), Report No. JNC TN9400 99-059 (in Japanese).

Yamaguchi, A., Takata, T. and Okano, Y., Numerical methodology to evaluate fast reactor sodium combustion, Nuclear Technology, Vol. 136 (2001), p.315-330.

Yamaguchi, A. and Tajima, Y., Validation study of computer code SPHINCS for sodium fire safety evaluation of fast reactor, Nuclear Engineering and Design, 219 (2003), pp.19-34. 